\title{
Fairly Assessing Students' Performance in Oral Defense Stage for Graduation Design of Major Civil Engineering
}

\author{
Xiaoshun $\mathrm{Wu}^{\mathrm{a}}$, Liping $\mathrm{Zuo}^{\mathrm{b}}$ \\ Nanchang Campus, Jiangxi University of Science and Technology, Ganzhou 341000, China; \\ awuxiaoshun1981@163.com, ${ }^{b} 780374986 @ q q . c o m$
}

Keywords: Civil engineering; graduation design; teaching reform; undergraduates

\begin{abstract}
Graduation design plays an important role in the cultivation of undergraduate students majoring in civil engineering. It aims to train students as skillful as possible by solving a complex project before they begin a new career. In order to improve the quality of graduation design, the oral defense stage was focused on. According to the characteristics of the conventional graduation design of major civil engineering, the problems in assessing students' work were firstly discussed. It is found that the limited time and questions, the difficulty of questions, the students' nervousness and the selected topics can greatly affect the students' performance, resulting in the unfairness of scoring students' work. Thus, it is suggested that the instructors' and reviewers' opinions, the introduction of direct instructors, a detailed scoring criterion, the students' on-site operations and the detailed assessment records should be comprehensively considered to fairly evaluate students’ work in their oral defense.
\end{abstract}

\section{Introduction}

Civil engineering [1] is a major which needs an abundance of practice training to make undergraduate students skillful enough. As a conclusion of four-year undergraduate college education, graduation design is of great importance because it is close to real projects [2]. Graduation design is also a vital practice training to develop students' creative ability and to improve their comprehensive quality [3]. It is so systematical and complex that it can provide students with a good chance to become more skillful before they start a new career. If undergraduate students do not master enough specialized knowledge learned in the past four years, it will be difficult for them to well finish the graduation design.

Unfortunately, lots of investigations have shown that the quality of graduation design is declining [4]. Generally speaking, the graduation design lasts about 12-16 weeks. Although the graduation design period is short, many students spend the valuable time in finding jobs or preparing for the graduate admission exams. Because of the convenience of the internets, students can easily download other people's final work of graduation design. Obviously, little time is needed for them to plagiarize other peoples' work. On the other hand, sometimes it is very difficult for teachers to distinguish the frauds. As a result, the students working independently may get a low score while the work of cheaters is often highly graded. Thus, some measurements are needed to fairly assess students' performance. If cheating is discovered, cheaters should be punished.

In order to improve the quality of graduation design, it is important to judge and prevent students' cheating. Teachers should spend enough time in monitoring the whole graduation design process, which includes stages of topic selection, thesis proposal, middle-term checking and oral defense [5]. In this paper, the stage of oral defense is focused on. The problems in assessing the students' work are firstly discussed. Some suggestions are then proposed to fairly evaluate the students' performance in their oral defense.

\section{Characteristics of Graduation Design of Major Civil Engineering}

In China, civil engineering is a major with numerous students because of the great market demands caused by increasing infrastructure construction. The cultivation of undergraduate students contributes greatly to the economic growth of China. Before students start a new career, they should undergo important practice training - graduation design, which is based on or close to real projects. It is so complex and comprehensive 
that it costs plenty of students' time and energy. A high rise, a large span roof structure, a bridge, or a foundation pit is usually selected as the graduation design topic. For any topic, specialized knowledge of building materials, mechanical principles, design rules, engineering drawing, linguistic ability and software operations is required. If a student does not well master the specialized knowledge, it will be difficult for him/her to complete graduation design successfully.

The final product of graduation design of major civil engineering normally includes the structural design drawings and the structural engineering calculations. It contains much information which reflects students' performance in graduation design. In order to well grade students' work, teachers should spend amount of time in checking their final products. It is noted that the oral defense stage is a vital part of the checking procedures. The results of this stage greatly affect the final scores of students. Teachers want to fairly assess students' performance in oral defense, and distinguish cheaters from other students. However, there exist some problems in the conventional oral defense stage for the graduation design of major civil engineering.

\section{Problems in Conventional Oral Defense}

\subsection{Problems caused by limited questions and time}

In the stage of oral defense, students are usually divided into several defense groups. Due to the increasing market demands, the number of students in civil engineering has been rising quickly in China. Generally speaking, 20-30 students are included in an oral defense group. There are so many students that only several minutes can be allocated to each student. Since time is limited, the number of questions is also finite.

For each oral defense group, the number of supervisory teachers in a thesis supervisory committee is generally 3-5. Since time is limited, only one question is allowed for each teacher after they quickly check a student's product. Such few questions can rarely cover the knowledge which should be mastered by students, because there are lots of knowledge points distributed in structural design principles, the structural mechanical calculations and the structural constructions, etc.

On the surface, a full checking for graduation design is conducted in the stage of oral defense since supervisory teachers ask questions in turn. Actually, the limited knowledge coverage caused by finite time and questions make it difficult for supervisory teachers to fully and fairly assess students' work. Cheaters can hardly be judged, neither.

\subsection{Problems caused by difficult questions}

The supervisory teachers in the same group ask questions in turn during the oral defense stage. For each student, the supervisory teachers usually ask random questions according to the contents of his/her final product. The difficulty of these questions can hardly be prescribed with an operational unified standard. Although teachers think what they ask is easy, students may still have feelings of difficulty. According to the teaching experiences, students often complain that they have bad luck and have to face difficult questions. It is noted that difficult questions cannot be well used to judge cheaters since most students defend themselves badly.

Similarly, teachers may also ask some easy questions. If a student is lucky enough, he may be confronted with only the easy questions. Thus, a student's performance in the oral defense heavily depends on the difficulty of questions. If a student working on his own fails to answer difficult questions but a cheater respond correctly to easy questions, it probably leads to a misjudgment. Therefore, it is improper for supervisory teachers to assess students' work based only on their answers in the oral defense stage. The difficulty of questions should be well estimated before the oral defense starts.

\subsection{Problems caused by students' nervousness}

The performance of students in the stage of oral defense can often be affected by students' psychological quality. Most students are nervous when facing so many strange supervisory teachers. They usually give disorganized answers when responding to teachers' questions. It is thus a little hard to judge whether the answers are right or not.

Besides, it seems that supervisory teachers’ personality also affects students' performance during their oral defense stage. Each supervisory teacher has his own personality. Some teachers are always with a 
serious look. When they ask questions, their solemn faces often make students nervous. Wrong responses are usually observed due to students' excessive nervousness. Some teachers are impatient, and often sharply criticize students. Even those students who work independently are afraid of teachers' criticism and often answer questions incorrectly. From this aspect, whether students finish their graduation design independently cannot be well judged in the oral defense stage.

\subsection{Problems caused by topic and teacher selection}

Because the number of students supervised by a teacher can usually reach 10-20, all kinds of topics are selected. The diversity of topics of graduation design makes it difficult for supervisory teachers to measure the final products with the same standard.

Besides, students tend to choose grandmotherly teachers as their direct supervisors. This kind of teachers is gracious and inclined to ask easy question in the oral defense stage. When students respond badly to their questions, gracious teachers may still give a high score. Thus, students supervised by a gracious teacher can obtain a high score more easily than other students in the oral defense stage. It is obviously unfair.

\section{Suggestions to Fairly Assess Students’ Performance in Oral Defense Stage}

\subsection{Assessment based on instructors' and reviewers' opinions}

The direct instructors are most familiar with their students' work because they have been monitoring the whole process of the students' graduation design. It is suggested that the daily attendance, the initiative in the work and the performance at each stage of the students are recorded by the direct instructors. The records provide a good reference for the supervisory teachers in the oral defense stage.

Except the records of process-monitoring, the reviewers' opinions are also important for other supervisory teachers. The students' final products need be reviewed by the direct instructors and some other reviewers before the oral defense begins. The instructors and reviewers carefully check the students' structural engineering calculations and structural drawings, and usually express their detailed opinions in a written form. Since the overall situations of students' graduation design are written down, the supervisory teachers attending the oral defense can have a global impression of all students' products. It is suggested that the results of reviewing students' final products are recorded in detail, including the assessment on innovation of topics, the integrity of the contents and the correctness of applying the knowledge points.

\subsection{Assessment based on the introduction of direct instructors}

Because a direct instructor monitors the whole process of his/her students' graduation design, he/she is much more familiar with the students' work than other supervisory teachers who attend the oral defense meeting. As discussed above, it is difficult for supervisory teachers to check students' products carefully in such a short time. It is better for the direct instructor to introduce his/her students' work before the oral defense begins. The key points and difficulty of students' topics as well as the levels of their efforts can be exhibited in the simple introduction. Other supervisory teachers can then be quickly familiar with the students’ products and rapidly construct some questions in a focused manner.

\subsection{Assessment based on a detailed scoring criterion}

It is suggested that detailed scoring criterion for oral defense are built up. The scoring criterion should be as clear as possible. It is expected to be displayed in tables. The criterion should reflect the quality of structural drawings, the logicality of structural engineering calculations, the clearness of the train of thought, the application of knowledge points and the ability of solving practical problems. With such a detailed scoring criterion, teachers can easily seize the scoring points of students' oral defense. It is noted that the scoring criterion should be published because students can make more targeted preparations for their oral defense.

\subsection{Assessment based on students' on-site operations}

Despite of the above suggestions, sometimes it is still difficult to distinguish the cheaters in the oral defense stage. It is noted that graduation design of major civil engineering is a practical training close to real projects. Some software such as PKPM, MIDAS, SAP2000, WORD and AUTO CAD are needed. If a student does not complete his/her graduation design on his/her own, it is impossible for him/her to skillfully operate 
these software. Even if some basic and simple operations are required, the cheaters cannot perform well enough. Therefore, it is suggested that on-site operations are employed in the oral defense stage. The students who are too strange with the common software is suspected cheaters. It is suggested that these suspects be further distinguished.

\subsection{Assessment results should be recorded}

In the oral defense stage of graduation design, the questions of supervisory teachers and the answers of students should be well recorded. The proficiency of students' operation on software should also be described and written down. The records of all groups are gathered and analyzed to grade each student's work. The top work and the worst products should be spent more attention based on the comprehensive analysis of their performance in all stages of the graduation design.

\section{Conclusion}

Graduation design is an important part in cultivating qualified undergraduate students majoring in civil engineering. Students receive a comprehensive and practice training by carrying out their graduation design. A student who works independently normally becomes more skillful before they start a new career. In order to improve the quality of graduation design, the oral defense stage is focused on in this paper. The graduation design of major civil engineering is complex and comprehensive, containing lots of knowledge points. The problems in assessing the students' work are mainly caused by the limited questions and time, the difficulty of questions, the students' nervousness and the diversity of topics. Correspondingly, it is suggested that the instructors' and reviewers' opinions, the introduction of direct instructors, a detailed scoring criterion, the students' on-site operations and the detailed assessment records should be paid enough attention, because they play a vital role in improving the fairness for assessing the students' performance during the oral defense stage of graduation design.

\section{Acknowledgment}

This paper is financially supported by the Doctoral Scientific Research Foundation of Jiangxi University of Science and Technology. Thanks Associate Professors Sidong Xu, Yuefang Hu and Hong Wang for their constructive advice.

\section{References}

[1]. Ministry of Education of the People's Republic of China, "University undergraduate course catalog," 1998.

[2]. F. Lv, "Exploration and practice of undergraduate engineering course's graduation project reform," Journal of Changchun University of Science and Technology, vol. 5, no. 1, pp. 156-157, January 2010. (In Chinese)

[3]. B. Yan, "Exploration and Practice of Guidance Mode about Engineering Course's Graduation Project-Guidance about Graduation Project for Students with Learning Difficulties,” 2014 International Conference on e-Education, e-Business and Information Management, pp. 329-331, April 2014.

[4]. M. Li, and Q. Deng, "Discussion on Graduation Design Topics for Undergraduates Majoring in Project Management,” 2013 International Conference on Education Technology and Information System, pp. 1062-1065.

[5]. Y. Gao, "Analysis of the norms of administration for graduation project and practical ability cultivation of college graduates,” Journal of Xi'an University of Post and Telecommunications, vol. 14, no. 3, pp. 156-159, May 2009. (In Chinese) 